\title{
Quản lý mô hình liên thế hệ tự giúp nhau của người cao tuổi và vai trò của công tác xã hội
}

\author{
Nguyễn Văn Đồng* \\ Trung tâm Đào tạo Kỹ năng Quốc tế Vietcess, \\ Tòa nhà Licogi 13, số 164 Khuất Duy Tiến, Thanh Xuân, Hà Nội, Việt Nam \\ Nhận ngày 16 tháng 01 năm 2017 \\ Chỉnh sửa ngày 22 tháng 02 năm 2017; Chấp nhận đăng ngày 22 tháng 3 năm 2017
}

\begin{abstract}
Tóm tắt: Thanh Hóa là địa phương đi đầu trong việc nhân rộng mô hình liên thế hệ tự giúp nhau, đây là mô hình chăm sóc - trợ giúp người cao tuổi dựa vào cộng đồng, mô hình đã huy động sự tham gia của cộng đồng trong việc chăm sóc, trợ giúp và phát huy vai trò người cao tuổi. Hoằng Hóa là huyện đầu tiên của tỉnh Thanh Hóa có loại mô hình này; sau giai đoạn đầu triển khai mô hình đã trợ giúp người cao tuổi thông qua 4 hoạt động chính: Chăm sóc sức khỏe; hỗ trợ sinh kế tạo việc làm; giải trí - thể dục thể thao; truyền thông nâng cao nhận thức về chính sách người cao tuổi. Nghiên cứu được thực hiện tại địa bàn huyện Hoằng Hóa ở 2 xã có mô hình liên thế hệ tự giúp nhau (xã Hoằng Lưu và Hoằng Trạch), mẫu nghiên cứu là 200 người cao tuổi có độ tuổi từ 60 - 80 tuổi, hiện đang sinh hoạt trong mô hình liên thể hệ tự giúp nhau tại địa bàn khảo sát.
\end{abstract}

Tù khóa: Liên thế hệ, tự giúp nhau, người cao tuổi, công tác xã hội.

\section{Thực trạng quản lý mô hình liên thế hệ tự giúp nhau tại địa bàn nghiên cứu}

\subsection{Hoạt động của mô hình liên thế hệ tư giúp nhau}

Theo Tổ chức Hỗ trợ Người cao tuổi Quốc tế - HAI văn phòng đại diện tại Việt Nam (Helpage International in Vietnam): "Mô hình liên thế hệ tự giúp nhau là mô hình được tổ chức hoạt động dựa vào cộng đồng, huy động nguồn lực từ phía cộng đồng để chăm sóc và trợ giúp người cao tuổi (NCT), dựa trên hai cách tiếp cận chính là liên thế hệ và tự giúp nhau nhằm tăng cường năng lực mọi mặt cho NCT

\footnotetext{
*ĐT.: 84-987089398

Email: nguyendong.sw@gmail.com
}

giúp họ khắc phục các khó khăn hạn chế trong đời sống" [1].

Năm 2008, mô hình liên thế hệ tự giúp nhau tại địa bàn huyện Hoằng Hóa (Thanh Hóa) được thành lập, mô hình triển khai trên phạm vi 2 xã Hoằng Lưu và xã Hoằng Trạch, ban đầu mô hình do Trung ương Hội Phụ nữ phối hợp với Tổ chức Hỗ trợ Người cao tuổi Quốc tế (HelpAge international Vietnam - HAI) và Trung ương Hội Người cao tuổi Việt Nam cùng với các tổ chức, đoàn thể tại địa phương thực hiện, ban đầu mô hình mới thành lập chỉ duy nhất có 1 hoạt động chủ đạo đó là hoạt động chăm sóc sức khỏe cho NCT từ đội ngũ tình nguyện viên. Đến năm 2012, sau khi có Chương trình Hành động Quốc gia về người cao tuổi (2012-2020) với định hướng nhân rộng hoạt động của mô hình, thì mô hình liên thế hệ tự giúp nhau phát triển thêm 3 hoạt động chính, 
đó là: Hoạt động hỗ trợ sinh kế tạo việc làm; hoạt động giải trí - Thể dục thể thao (TDTT) và hoạt động truyền thông nâng cao nhận thức cho người cao tuổi NCT về chính sách. Vì vậy, hiện nay mô hình liên thế hệ tự giúp nhau tại địa bàn huyện Hoằng Hóa (gồm xã Hoằng Lưu và xã Hoằng Trạch) đang có 4 hoạt động chủ đạo: Hoạt động chăm sóc sức khỏe cho NCT; hoạt động hỗ trợ sinh kế tạo việc làm; hoạt động giải trí - TDTT và hoạt động truyền thông nâng cao nhận thức cho $\mathrm{NCT}$ về chính sách nhằm trợ giúp về mọi mặt cho NCT [1].

Hoạt động chăm sóc sức khỏe cho NCT từ đội ngũ tình nguyện viên, những NCT sống cô đơn, NCT có sức khỏe yếu và có nhu cầu trợ giúp sẽ được tình nguyện viên đến trợ giúp về mọi mặt. Tình nguyện viên cũng phối hợp với cán chính quyền địa phương tổ chức các chương trình truyền thông tư vấn trang bị những kiến thức và kỹ năng chăm sóc sức khỏe cho NCT, tổ chức khám bệnh định kì cho NCT và hướng dẫn cách rèn luyện sức khỏe cho NCT.

Hoạt động hỗ trợ sinh kế tạo việc làm, cho vay vốn bằng hiện vật (cây trồng, vật nuôi) và hướng dẫn, tập huấn kỹ thuật sản xuất kinh doanh; tổ chức cho NCT vay vốn để sản xuất, sau đó trả lãi và gốc cho CLB để quay vòng cho các thành viên khác vay (có thể vay theo nhóm), mỗi NCT được vay với số tiền từ 3-5 triệu đồng, tùy thuộc mục đích hoạt động sản xuất.

Hoạt động giải trí, TDTT đây là hoạt động được mô hình tổ chức thường xuyên cho các CLB liên thôn, trong hoạt động này NCT được tham gia giao lưu, giải trí, rèn luyện sức khỏe như: CLB sáng tác thơ, CLB văn nghệ, tổ chức tham quan, du lịch, học hỏi - chia sẻ kinh nghiệm sống; CLB thể dục dưỡng sinh rèn luyện sức khỏe. Đây là hoạt động thu hút được đông đảo NCT tham gia, các hoạt động cụ thể trong mô hình phù hợp với đặc thù của mọi đối tượng NCT tham gia.

Hoạt động truyền thông nâng cao nhận thức về chính sách cho NCT, đây là hoạt động rất có ý nghĩa, với phương châm trợ giúp pháp lý mọi mặt cho NCT, giúp NCT thuận lợi trong việc tiếp cận quyền và lợi ích từ chính sách trợ giúp xã hội; hỗ trợ giải quyết những khó khăn và vướng mắc khi NCT tiếp cận chính sách. Trong hoạt động này NCT thường xuyên được tham gia các buổi truyền thông, tập huấn nâng cao hiểu biết về chính sách. Các CLB trong mô hình được thành lập với mục đích bảo vệ quyền và lợi ích cho NCT; giám sát việc thực hiện chính sách NCT tại địa phương; tuyên truyền về Luật và các chính sách, hỗ trợ, giám sát thực hiện chế độ cho NCT [2].

\subsection{Tổ chức của mô hình liên thế hệ tư giúp nhau}

Mô hình liên thế hệ tự giúp nhau tại xã Hoằng Lưu và xã Hoằng Trạch là tổ chức dựa vào cộng đồng, mô hình được tổ chức ở cấp thôn dưới dạng câu lạc bộ (CLB), mỗi CLB liên thế hệ tự giúp nhau có từ $50-70$ thành viên, trong đó $70 \%$ là NCT, $30 \%$ là các đối tượng trẻ tuổi hơn và có điều kiện kinh tế khá giả. $70 \%$ là đối tượng thuộc diện nghèo, cận nghèo hoặc những người có hoàn cảnh khó khăn. Mô hình nhằm thực hiện 2 mục tiêu: Tạo cơ hội cho NCT đang sinh hoạt trong CLB được cải thiện đời sống của bản thân, gia đình và cộng đồng; giúp NCT tăng cường vai trò và sự đóng góp của họ trong cải thiện sức khỏe, thu nhập và phát triển ở địa phương.

Mô hình CLB liên thế hệ tự giúp nhau tại xã Hoằng Lưu và xã Hoằng Trạch đạt được những thành công bước đầu là nhờ biết cách tổ chức, cách huy động được sự tham gia của cộng đồng, huy động nguồn lực từ nhiều phía và đặc biệt có vai trò quản lý, điều hành - điều phối của đội ngũ cán bộ, nhân viên giàu kinh nghiệm chuyên môn và tận tâm, nhiệt tình, tâm huyết với công tác chăm sóc, trợ giúp NCT. Các thành tựu đạt được của mô hình của 2 xã cần kể đến:

Là mô hình được tổ chức hoạt động dựa vào cộng đồng, phát huy được sự giúp nhau của các thành viên trẻ hơn, những người có kinh nghiệm sản xuất để trợ giúp NCT. Thành viên CLB từ 50-70 người, trong đó: $70 \%$ là $\mathrm{NCT}(60$ tuổi trở lên/55 tuổi đối với nữ); 60-70\% là phụ nữ cao tuổi. 
Trong cách thức quản lý, mô hình có cách thức quản lý CLB rất khoa học, CLB tự quản lý, có kế hoạch, báo cáo hàng tháng, tất cả được công khai, minh bạch trước tập thể. Quy trình quản lý bằng sổ sách và có tài liệu hướng dẫn kèm theo, rất dễ hiểu, dễ tiếp cận. Mỗi CLB đều có một ban chủ nhiệm, mỗi ban chủ nhiệm tối thiểu là 5 người, gồm: cán bộ Hội Người cao tuổi, cán bộ Hội Phụ nữ, cán bộ Mặt trận Tổ quốc, cán bộ Hội Cựu chiến binh, cán bộ Hội Nông dân, cán bộ Hội Chữ thập đỏ, cán bộ Đoàn Thanh niên.

Mô hình có đội ngũ tình nguyện viên trợ giúp NCT khó khăn ở cộng đồng và bảo vệ quyền lợi cho NCT, mỗi CLB có 7-10 tình nguyện viên luôn theo sát các hoạt động diễn ra trong CLB. Đội ngũ tình nguyện viên là những nhân viên thuộc mô hình liên thế hệ tự giúp nhau, trước khi triển khai hoạt động can thiệp trợ giúp cho NCT, đội ngũ này thường xuyên được tập huấn trang bị các kiến thức, kỹ năng, kỹ thuật chuyên môn để hướng dẫn, tư vấn, trợ giúp cho NCT một cách khoa học, bài bản và hiệu quả nhất [1].

Mô hình tổ chức các hoạt động mang tính toàn diện như: nâng cao mức sống, tăng thu nhập, cải thiện sức khoẻ, cải thiện đời sống tinh thần qua hoạt động giải trí - văn nghệ, truyền thông bảo vệ quyền và lợi ích, tự giúp nhau/hỗ trợ cộng đồng... các CLB tại mỗi xã sinh hoạt mỗi tháng ít nhất 2 lần để báo cáo tình hình hoạt động của CLB và triển khai công việc trong thời gian tiếp theo.

Hầu hết các CLB liên thế hệ tự giúp nhau tại xã Hoằng Lưu và Hoằng Trạch đã và đang hoạt động có hiệu quả, được cán bộ và nhân dân tại địa phương đánh giá đây là mô hình mang tính nhân văn sâu sắc và góp phần chăm sóc đời sống vật chất, tinh thần và phát huy vai trò của NCT trong cộng đồng. Mô hình liên thế hệ tự giúp nhau tại địa phương được nhiều chuyên gia tổ chức HAI và các cơ quan chuyên môn đánh giá là một mô hình toàn diện, mô hình chính là giải pháp hiệu quả để hỗ trợ NCT nghèo, cận nghèo, NCT khó khăn cụ thể như:
Qua mô hình chứng minh là NCT hoàn toàn có khả năng sử dụng vốn có hiệu quả, tỷ lệ hoàn trả $100 \%$ và đúng hạn, góp phần giải quyết tình trạng nghèo đói, thu nhập thấp của NCT và gia đình của họ thông qua việc tiếp cận với vốn vay (bằng tiền hoặc bằng hiện vật: cây giống hoặc con giống, phương tiện kỹ thuật), hướng dẫn sản xuất kinh doanh quy mô nhỏ để đảm bảo tăng thu nhập, cải thiện mức sống.

Cải thiện tình trạng sức khoẻ cho NCT nghèo, cận nghèo và cộng đồng thông qua tổ chức phong trào rèn luyện sức khoẻ, truyền thông về phòng ngừa, điều trị bệnh và khám bệnh định kỳ, được tổ chức thường xuyên.

Bảo vệ quyền của NCT bị thiệt thòi thông qua các hoạt động trợ giúp pháp lý, giám sát thực hiện Luật NCT và hỗ trợ NCT hưởng đầy đủ chế độ, giúp đỡ các đối tượng NCT ốm đau, gặp khó khăn bằng hệ thống tình nguyện viên.

Đặc biệt, mô hình liên thế hệ tự giúp nhau tại xã Hoằng Lưu và xã Hoằng Trạch đã huy động sự tham gia của chính quyền và nhân dân địa phương, nhất là những người trẻ hơn giúp đỡ NCT; đồng thời, khuyến khích NCT tự vươn lên, đóng góp vào sự phát triển của địa phương thông qua các hoạt động của CLB như tham gia giúp đỡ những người khó khăn, giữ gìn vệ sinh, bảo vệ môi trường và các phong trào của khu dân cư đang sinh sống.

Mô hình tại địa phương đã góp phần nâng cao nhận thức về vai trò và sự tham gia của NCT địa phương. Bên cạnh đó, giúp đỡ Nhà nước và địa phương làm tốt công tác chăm sóc, trợ giúp và phát huy vai trò NCT, tạo cầu nối giữa NCT với cộng đồng và các nguồn lực trong cộng đồng [2].

\section{Vai trò của công tác xã hội trong quản lý mô hình liên thế hệ tự giúp nhau tại địa bàn nghiên cứu}

\subsection{Vai trò bán chuyên nghiệp của nhân viên} CTXH trong mô hình liên thế hệ tư giúp nhau

Người cao tuổi thuộc nhóm đối tượng can thiệp trọng tâm của nghề công tác xã hội, nghề 
công tác xã hội với NCT ở Việt Nam tuy còn khá mới mẻ, song lại là một nghề có tiềm năng và triển vọng lớn. Năm 2010, Đề án phát triển nghề công tác xã hội được ban hành, đây chính là cơ sở pháp lý quan trọng đưa nghề công tác xã hội ở nước ta phát triển theo hướng chuyên nghiệp. Cuối năm 2011, nước ta lại chính thức bước vào giai đoạn già hóa dân số, nhóm dân số cao tuổi tăng nhanh và chạm ngưỡng 9 triệu người (chiếm 10,5\% tổng dân số cả nước, năm 2014), NCT thuộc nhóm đối tượng can thiệp trọng tâm của nghề công tác xã hội. Vì vậy, đây chính là cơ hội để phát triển mạng lưới nghề công tác xã hội với NCT, nhất là những mô hình can thiệp trợ giúp dựa vào cộng đồng như mô hình liên thế hệ tự giúp nhau [3].

Trong nghiên cứu này, tác giả đi sâu phân tích vai trò bán chuyên nghiệp của nhân viên xã hội trong mô hình, được thực hiện bởi đội ngũ cán bộ, nhân viên, tình nguyện viên là những nhân viên xã hội đang trực tiếp chăm sóc - trợ giúp NCT trong mô hình liên thế hệ tự giúp nhau tại địa bàn, đó là những nhân viên xã hội tuy chưa được đào tạo bài bản về chuyên nghành công tác xã hội, nhưng hoạt động mà họ đang thực hiện và vai trò họ đang đảm nhận đấy chính là hoạt bán chuyên nghiệp của người làm công tác xã hội. Họ chính là những người tốt nghiệp từ nhiều chuyên nghành khác nhau như: Y tế công cộng, xã hội học, công tác xã hội, tâm lý học, sư phạm, quản trị nhân lực, kinh tế... và những tình nguyện viên có trình độ trung cấp, sơ cấp được đào tạo tập huấn qua những khóa nghiệp vụ ngắn hạn trong hoạt động can thiệp, trợ giúp cho NCT, họ có kinh nghiệm công tác lâu năm trong nghề, cùng nhiệt huyết, lòng nhiệt tình và có trách nhiệm với $\mathrm{NCT}$, đấy chính là nền tảng quan trọng giúp mọi hoạt động can thiệp - trợ giúp của họ đạt được hiệu quả tốt. Vì vậy, trong nghiên cứu này tác giả tiến hành phân tích vai trò bán chuyên nghiệp của nhân viên xã hội trong mô hình, trên cơ sở phân tích thực trạng thực hiện vai trò này trong các hoạt động của mồ hình, tác giả đề xuất hoạt động công tác xã hội chuyên nghiệp trong mô hình với vai trò của nhân viên công tác xã hội.

\subsubsection{Vai trò của nhân viên xã hội trong} hoạt động chăm sóc sức khỏe cho NCT trong mô hình

Trong hoạt động chăm sóc sức khỏe (CSSK) cho NCT trong mô hình liên thế hệ tự giúp nhau, những nhân viên xã hội hiện đang trực tiếp và gián tiếp trong can thiệp - trợ giúp NCT có những vai trò như: Tư vấn, hướng dẫn cách phòng bệnh cho NCT; trang bị kiến thức, kỹ năng CSSK cho NCT; hỗ trợ vận động hằng ngày; hỗ trợ trong sinh hoạt hằng ngày; cấp phát thuốc men, các dụng cụ cần thiểt... Biểu 2.1. thể hiện kết quả khảo sát về vai trò của nhân viên xã hội trong hoạt động CSSK:

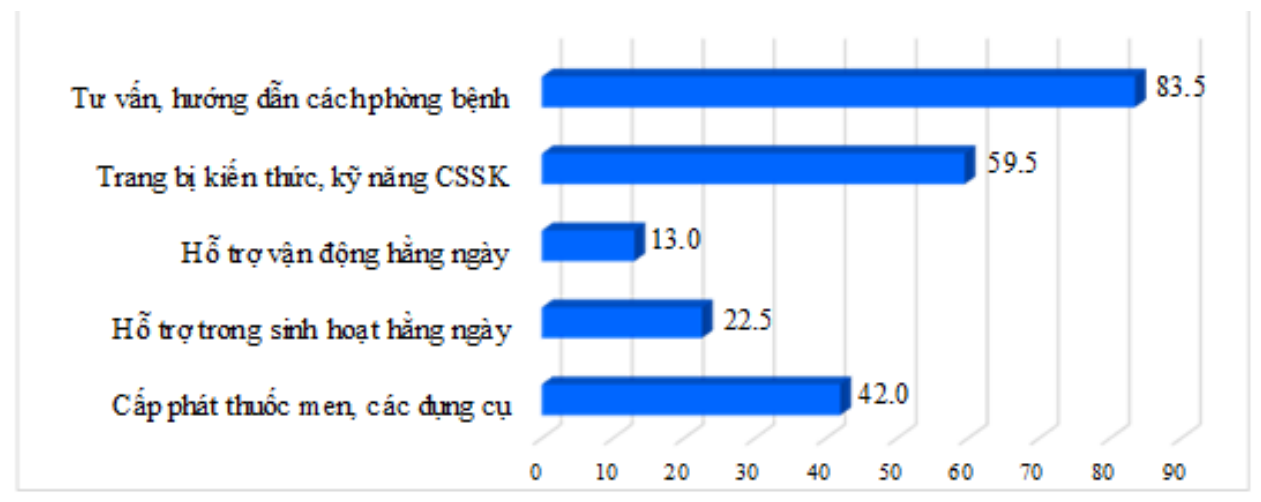

Biểu 2.1. Vai trò của nhân viên xã hội trong hoạt động chăm sóc sức khỏe cho NCT (Đơn vị:\%; N=200)

(Nguồn: Kết quả khảo sát tại địa bàn nghiên cứu) 
Trong tổng số 200 NCT tham gia khảo sát thuộc địa bàn 2 xã Hoằng Lưu và xã Hoằng Trạch, chiếm tỷ lệ cao nhất là số NCT cho biết vai trò của nhân viên xã hội trong hoạt CSSK đó là vai trò "Tư vấn, hướng dẫn cách phòng bệnh" $(83,5 \%)$, vai trò này gắn với những hoạt động mà NCT thường thấy ở nhân viên xã hội khi thực hiện hoạt động trợ giúp họ, với vai trò này những nhân viên xã hội thường tư vấn hướng dẫn cho NCT các cách nhận biết và phòng ngừa bệnh tật, CSSK như thế nào để phòng ngừa bệnh tật tốt nhất, kể cả tư vấn cách tập luyện và chế độ ăn uống phù hợp, nhằm duy trì sức khỏe tốt. Ngoài ra, nhân viên xã hội còn phối hợp với cán bộ mô hình và chính quyền để tổ chức các hoạt động truyền thông về CSSK cho tất cả NCT trong CLB, hoạt động này diễn ra 1 lần/tháng.

Số NCT cho biết vai trò của nhân viên xã hội trong hoạt động CSSK đó là "Trang bị kiến thức, kỹ năng CSSK" chiếm tỷ lệ cao thứ hai với $59,5 \%$ số người tham gia trả lời, đây chính là vai trò gắn với những trợ giúp $\mathrm{NCT}$ thường thấy và họ thường nhận được ở nhân viên xã hội, các kiến thức, kỹ năng về CSSK NCT được trang bị như: ăn uống, sinh hoạt, tập luyện phù hợp để duy trì một sức khỏe tốt, cách nhận biết và phòng tránh những rủi ro bệnh tật hay mắc phải do tuổi già... những kiến thức - kỹ năng về CSSK được trang bị phù hợp với điều kiện sức khỏe và nhu cầu CSSK của NCT.

Khi tham gia hoạt động CSSK, NCT còn được cung cấp thuốc men, các vật dụng cần thiết để CSSK do mô hình hỗ trợ, chính vì vậy có $42,0 \%$ số NCT cho biết nhân viên xã hội trong hoạt động này còn có vai trò "Cấp phát thuốc men, các dụng cụ”, vai trò này của nhân viên xã hội gắn với những hoạt động trợ giúp mà nhân viên xã hội vẫn trợ giúp NCT thường xuyên, những loại thuốc được cấp phát theo đơn, theo tình trạng bệnh tình và sức khỏe, ngoài ra những dụng cụ đựng đồ ăn, nước uống, khăn lau cũng được mô hình hỗ trợ cho NCT.

Ngoài ra, còn có $22,5 \%$ số NCT tham gia khảo sát cho biết, trong hoạt động CSSK nhân viên xã hội còn có vai trò "Hỗ trợ trong sinh hoạt hằng ngày" cho NCT có sức khỏe yếu, sống cô đơn, mắc bệnh tật mãn tính... những trợ giúp này của nhân viên xã hội chủ yếu là những hỗ trợ về: vệ sinh cá nhân tắm gội, quét dọn lau dọn nhà cửa, trợ giúp trong vấn đề ăn uống... Những công việc này được nhân viên xã hội thực hiện thường xuyên 3-4 buổi/tuần đối với NCT trọng diện được hỗ trợ. Bên cạnh đó, có 13,0\% số NCT cho biết trong hoạt động này, nhân viên xã hội có vai trò "Hỗ trợ vận động hằng ngày" cho $\mathrm{NCT}$, số $\mathrm{NCT}$ nhận được những trợ giúp này chủ yếu là NCT có sức khỏe yếu, bị bệnh mãn tính; nhân viên xã hội đến nhà theo lịch 3-4 buổi/tuần để hỗ trợ NCT đi lại, vận động thân thể, xoa bóp xương khớp giúp NCT dễ chịu và thoải mái hơn.

Như vậy, có thể thấy trong hoạt động CSSK vai trò thực tế của người nhân viên xã hội là những hoạt động rất thiết thực đối với $\mathrm{NCT}$, từ chức năng tư vấn và trang bị kiến thức về CSSK cho đến hoạt động trợ giúp NCT vận động, những hỗ trợ bên ngoài như trợ giúp sinh hoạt hằng ngày, muốn thực hiện được những vai trò này người nhân viên xã hội cần phải là người được tập huấn những kỹ năng chuyên môn về chăm sóc - trợ giúp NCT, có tính kiên trì, nhiệt huyết và trách nhiệm đối với công việc của mình.

2.1.2. Vai trò của nhân viên xã hội trong hoạt động hỗ trọ sinh kế tạo việc làm cho NCT trong mô hình

Tham gia hoạt động hỗ trợ sinh kế tạo việc làm trong mô hình liên thế hệ tự giúp nhau, nhân viên xã hội có những vai trò như: Đào tạo, tập huấn kiến thức và kỹ thuật sản xuất cho NCT; cùng với NCT lập và triển khai kế hoạch; kết nối NCT với các nguồn vốn, phương tiện kỹ thuật; tham gia giám sát hoạt động sản xuất; cùng với NCT đánh giá kết quả đạt được... Biểu 2.2. thể hiện kết quả khảo sát về vai trò của nhân viên xã hội trong hoạt động hỗ trợ sinh kế tạo việc làm: 
Đơn vị: \%; $\mathrm{N}=200$

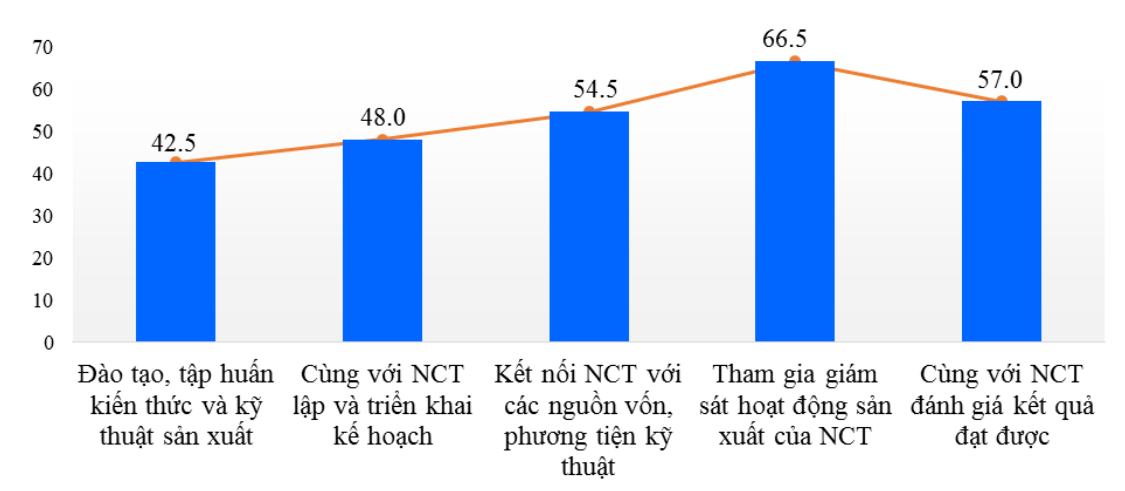

Biểu 2.2. Vai trò của nhân viên xã hội trong hoạt động hỗ trợ sinh kế tạo việc làm cho NCT.

(Nguồn: Kết quả khảo sát tại địa bàn nghiên cưu)

Trong tổng số 200 NCT tham gia khảo sát thuộc địa bàn 2 xã Hoằng Lưu và xã Hoằng Trạch, số NCT cho biết vai trò của nhân viên xã hội trong hoạt động hỗ trợ sinh kế tạo việc làm đó là "Tham gia giám sát hoạt động sản xuất của NCT" chiếm tỷ lệ NCT tham gia trả lời cao nhất với $66,5 \%$, đây chính là vai trò gắn với hoạt động của nhân viên xã hội thường ngày trong mô hình, những nhân viên xã hội thường xuống địa bàn trực tiếp tham gia hoạt động sản xuất với $\mathrm{NCT}$, giám sát để kịp thời góp ý, điều chỉnh phương pháp và kỹ thuật sản xuất phù hợp cho NCT, đây chính là hoạt động mà NCT cho biết nó thường xuyên được diễn ra hàng tuần và hàng tháng ở các CLB mà họ đang tham gia sinh hoạt.

Chiếm tỷ lệ cao thứ hai với $57,0 \%$ số NCT tham gia trả lời cho biết nhân viên xã hội có vai trò "Cùng với $\mathrm{NCT}$ đánh giá kêt quả đạt được", đây chính là vai trò gắn với những hoạt động thường diễn ra trong mô hình, theo lịch hàng tuần, hàng tháng và hàng quý, hàng năm và trải qua từng giai đoạn nhân viên xã hội đều cùng với NCT đánh giá lại những kết quả đạt được thời gian qua và đề ra những mục tiêu, định hướng, kế hoạch triển khai nhiệm vụ công việc và các hoạt động sắp tới.

Số NCT cho biết vai trò của nhân viên xã hội trong hoạt động hỗ trợ sinh kế tạo việc làm là "Kết nối NCT với các nguồn vốn, phương tiện kỹ thuật" chiếm $54,5 \%$ số NCT tham gia trả lời, vai trò này thường gắn với những hoạt động kết nối NCT với những nguồn vốn vay như tiền, hiện vật... để NCT thuận lợi trong việc sản xuất của mình. Hiện tại, mổ hình đang triển khai hai hình thức vay vốn đó là vay bằng tiền mặt (từ 3-5 triệu/người) và vay bằng hiện vật (cây giống và con giống), NCT sau khi vay đến hạn phải trả cả gốc lẫn lãi để lấy nguồn quay vòng cho NCT khác vay, nếu đến hạn NCT vẫn chưa trả được thì có thể gia hạn, tuy nhiên với sự kết nối khá hiệu quả của nhân viên xã hội cùng những kiến thức - kỹ thuật được tập huấn, NCT đã sử dụng khá hiệu quả nguồn vốn vay.

Có 48,0\% số NCT cho biết vai trò của nhân viên xã hội trong hoạt động hỗ trợ sinh kế tạo việc làm đó là "Cùng với $\mathrm{NCT}$ lập và triển khai kế hoạch", vai trò này của nhân viên xã hội gắn với những hoạt động trợ giúp hàng tháng, đến thời điểm họp đánh giá công việc và các hoạt động trong tháng NCT và nhân viên xã hội luôn tập trung thảo luận về kế hoạch triển khai công việc trước mắt để đưa ra một bản kế hoạch cụ thể và xác định nhiệm vụ của mỗi bên tham gia trong suốt quá trình thực hiện kế hoạch trong tháng, tất cả các hoạt động và công việc này đều có vai trò kết hợp sự giám sát thường xuyên của nhân viên xã hội.

Cuối cùng là số NCT cho biết vai trò của nhân viên xã hội trong hoạt động này đó là "Đào tạo, tập huấn kiến thức và kỹ thuật sản xuất" chiếm $42,5 \%$ số NCT tham gia trả lời, vai trò này gắn với những hoạt động đào tạo và tập huấn trang bị kiến thức - kỹ thuật sản xuất trực 
tiếp tại các lớp tập huấn mà NCT tham gia, ngoài ra những kiến thức - kỹ thuật này còn được chia sẻ tại các buổi truyền thông chung cho toàn bộ CLB và trực tiếp thực địa dưới địa bàn, với những hoạt động thử nghiệm thực tế dưới địa bàn để NCT thấy được phương pháp và kỹ thuật ứng dụng.

Như vậy, có thể thấy được trong hoạt động hỗ trợ sinh kế tạo việc làm, nhân viên xã hội có vai trò khá toàn diện, từ khâu đào tạo tập huấn trang bị kiến thức - kỹ thuật sản xuất cho NCT đến mảng kết nối huy động nguồn vốn vay cho NCT và cùng tham gia các hoạt động thực tế với NCT dưới địa bàn, kết thúc đưa ra những đóng góp, đánh giá, giúp NCT củng cố được những kiến thức - kỹ thuật sản xuất hiệu quả, ứng dụng vào thực tiễn hoạt động sản xuất của mình.

2.1.3. Vai trò của nhân viên xã hội trong hoạt động giải trí, TDTT của NCT trong mô hìn

Trong hoạt động giải trí - TDTT của NCT trong mô hình liên thế hệ tự giúp nhau, NCT cho biết nhân viên xã hội có những vai trò sau: Cùng với NCT tổ chức các hoạt động văn hóa, văn nghệ; tổ chức các hoạt động tham quan, học hỏi, chia sẻ kinh nghiệm; tổ chức các hoạt động vận động rèn luyện sức khỏe cho NCT; tuyên truyền về lợi ích của việc giải trí, TDTT ở NCT... Biểu 2.3. thể hiện kết quả khảo sát về vai trò của nhân viên xã hội trong hoạt động giải trí - TDTT:

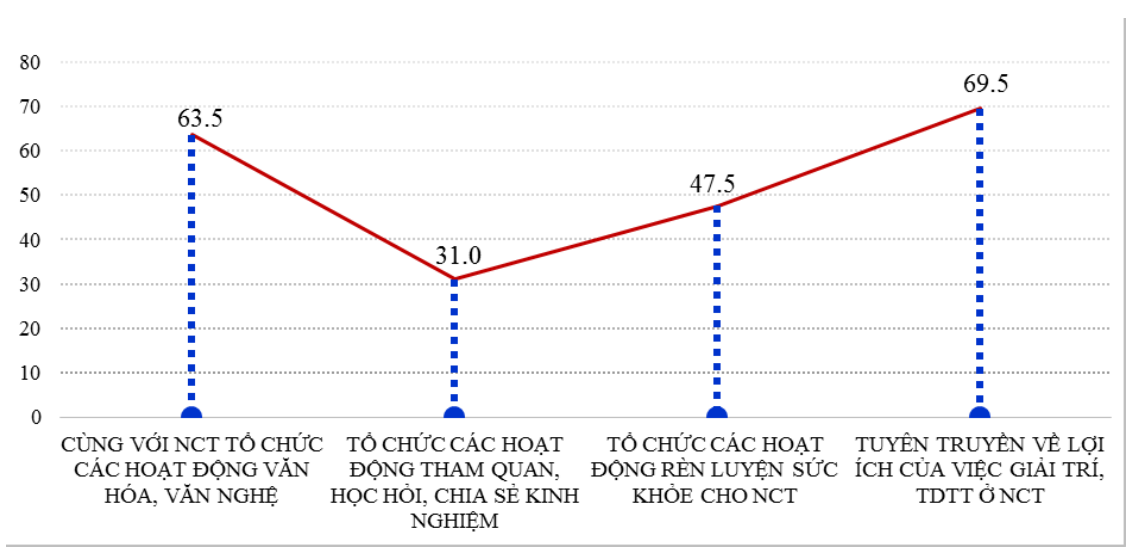

Biểu 2.3. Vai trò của nhân viên xã hội trong hoạt động giải trí - TDTT của NCT (Đơn vị: \%; $\mathrm{N}=200$ ).

(Nguồn: Kết quả khảo sát tại địa bàn nghiên cứu)

Trong tổng số $200 \mathrm{NCT}$ tham gia khảo sát tại địa bàn 2 xã Hoằng Lưu và xã Hoằng Trạch cho biết, trong hoạt động giải trí - TDTT mà họ đang tham gia thì nhân viên xã hội có vai trò "Tuyên truyền về lợi ích của việc giải trí, TDTT ở NCT", đây chính là vai trò gắn với những hoạt động truyền thông chia sẻ về những lợi ích và những tác động tích cực của việc tham gia hoạt động giải trí - TDTT, hoạt động tuyên truyền thường xuyên được nhân viên xã hội thực hiện tại các CLB 1-2 lần/tháng, với việc thực hiện hoạt động này nhân viên xã hội đã chuyển tải được các thông tin, thông điệp về lợi ích của việc tham gia hoạt động giải trí - TDTT tới mọi đối tượng $\mathrm{NCT}$ và người dân tại địa phương, tác động nhằm thay đổi thói quen, suy nghĩ, nhận thức của NCT về vấn đề giải trí TDTT mang lại nhiều lợi ích thiết thực, cải thiện đời sống tinh thần cho NCT.

Có 63,5\% số NCT có biết trong hoạt động giải trí - TDTT, nhân viên xã hội còn có vai trò "Cùng với NCT tổ chức các hoạt động văn hóa, văn nghệ", vai trò này của nhân viên xã hội chủ yếu thực hiện phối hợp với các CLB dưới các 
địa bàn, cùng tham gia làm công tác tổ chức nhân viên xã hội sẽ chia sẻ những góp ý, định hướng và kinh nghiệm tổ chức các hoạt động này ở các $C L B$ khác họ đã làm được gì và những gì nên học hỏi, cần tăng cường những hoạt động văn hóa - văn nghệ mang ý nghĩa tinh thần này, giúp tăng cường sự tham gia của NCT vào các hoạt động của cộng đồng, giúp NCT có đời sống tinh thần phong phú hơn.

Bên cạnh đó, có $47,5 \%$ số NCT cho biết trong hoạt động giải trí - TDTT, nhân viên xã hội còn có vai trò "Tổ chức các hoạt động rèn luyện sức khỏe cho NCT", vai trò này gắn với những hoạt động phối hợp với các CLB tổ chức những hoạt động rèn luyện thể chất tăng cường sức khỏe cho NCT tại các CLB, được thực hiện 1-2 lần/tháng, nhân viên xã hội là người đóng vai trò tổ chức và tham dự các hoạt động này để đóng góp, chia sẻ những kinh nghiệm và cùng với NCT định hướng hoạt động này, để hoạt động đạt được hiệu quả cao và đáp ứng được nhu cầu rèn luyện sức khỏe của NCT trong CLB.

Số NCT cho biết nhân viên xã hội có vai trò "Tổ chức các hoạt động tham quan, học hỏi, chia sẻ kinh nghiệm" chiếm 31,0\% NCT tham gia trả lời, vai trò này gắn với những hoạt $\mathrm{du}$ lịch và tham quan, với hai mục đích: giải trí và học hỏi kinh nghiệm từ việc triển khai tổ chức các hoạt động giải trí - TDTT trong mô hình, đây chính là những hoạt động rất có ý nghĩa; hàng tháng, hàng quý nhân viên xã hội trong mô hình sẽ cùng với NCT tổ chức các hoạt động tham quan - du lịch này, thành phần tham gia là NCT thuộc chủ nhiệm các CLB, những NCT tích cực có thành tích tốt trong các hoạt động của CLB.

Có thể thấy rằng, vai trò của nhân viên xã hội trong mảng hoạt động giải trí - TDTT rất quan trọng, đảm nhận từ khâu tuyên truyền đến khâu phối hợp cùng với NCT tổ chức các hoạt động tinh thần như: văn hóa, văn nghệ, giải trí... cho đến nhưng hoạt động tham quan, du lịch, học hỏi, chia sẻ kinh nghiệm tổ chức mô hình và tổ chức các hoạt động rèn luyện sức khỏe cho NCT... Để thực hiện những vai trò này, nhân viên xã hội phải là người có kiến thức - kỹ năng, am hiểu về đời sống tinh thần của NCT, các hoạt động văn hóa - văn nghệ, hoạt động rèn luyện sức khỏe liên quan đến NCT.

\subsubsection{Vai trò của nhân viên xã hộ trong} hoạt động truyền thông nâng cao nhận thức về chính sách cho NCT

Trong hoạt động truyền thông nâng cao nhận thức về chính sách cho NCT, theo chia sẻ của NCT, nhân viên xã hội có những vai trò chủ đạo như: Kết nối NCT tiếp cận chính sách trợ giúp; cung cấp thông tin về các chính sách trợ giúp; tư vấn cách giải quyết khó khăn, vướng mắc cho NCT; biện hộ cho NCT gặp khó khăn về chính sách"; trợ giúp pháp lý về mọi mặt... Biểu 2.4. thể hiện kết quả khảo sát về vai trò của nhân viên xã họi trong hoạt động truyền thông nâng cao nhận thức về chính sách:

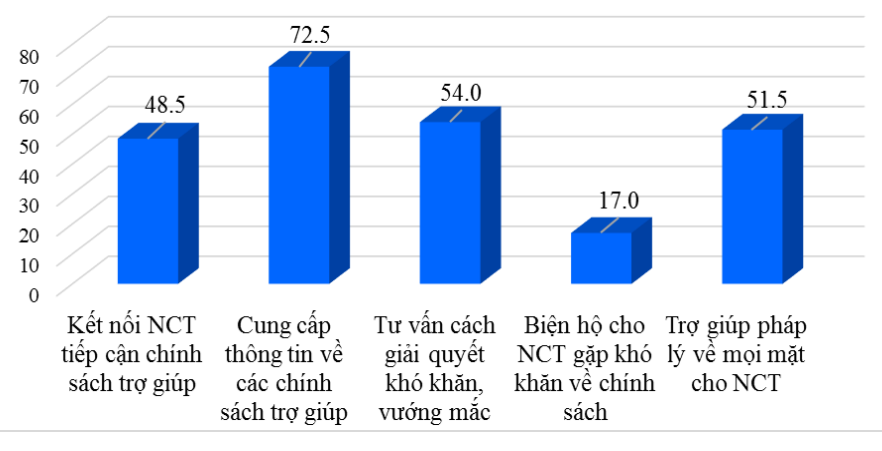

Biểu 2.4. Vai trò của nhân viên xã hội trong hoạt động truyền thông nâng cao nhận thức về chính sách cho NCT.

(Đơn vị:\%; $\mathrm{N}=200$ ) (Nguồn: Kết quả khảo sát tại địa bàn nghiên cứu) 
Trong tổng số 200 NCT tham gia khảo sát tại địa bàn hai xã Hoằng Lưu và xã Hoằng Trạch, số NCT cho biết trong hoạt động truyền thông nâng cao nhận thức về chính sách, có $72,5 \%$ số NCT cho biết nhân viên xã hội có vai trò "Cung cấp thông tin về các chính sách trợ giúp", thực tế vai trò này thuộc về cán bộ chính sách xã hội tại địa phương, tuy nhiên hiện nay mô hình đang có sự phối hợp với chính quyền địa phương để nhân viên xã hội trong mô hình phối hợp với cán bộ chính sách của địa phương thực hiện vai trò này, vừa là để giảm gánh nặng cho cán bộ chính sách (do số lượng cán bộ tại xã rất ít chỉ có 1 người không thể thực hiện hết vai trò) vừa là để tuyên truyền thông tin về chính sách sẽ hiệu quả hơn do sử dụng nhiều cách tiếp cận khác nhau, giúp NCT dễ hiểu.

Tiếp theo là số NCT cho biết trong hoạt động truyền thông nâng cao nhận thức về chính sách, nhân viên xã hội còn có vai trò "Tư vấn cách giải quyết khó khăn, vướng mắc" cho NCT trong quá trình tiếp cận chính sách, vai trò này thường được nhân viên xã hội thực hiện thường xuyên, gắn với các hoạt động trợ giúp như: quy trình, đối tượng, chế độ, quyền lợi, thời gian thụ hưởng và những thủ tục hồ sơ giấy tờ liên quan cần chuẩn bị... Đây là vai trò đòi hỏi người nhân viên xã hội phải có những hiểu biết nhất định về chính sách trợ giúp xã hội và các văn bản pháp luật để tư vấn, giải đáp cho NCT một cách hiệu quả, đồng thời nhân viên xã hội cũng phải có kỹ năng tư vấn để NCT cảm thấy yên tâm và được thỏa mãn khi được giải đáp khúc mắc.

Có $51,5 \%$ số NCT cho biết vai trò của nhân viên xã hội trong hoạt động truyền thông nâng cao nhận thức về chính sách đó là "Trợ giúp pháp lý về mọi mặt cho NCT", đây chính là vai trò chung, được xem là vai trò tổng hợp của NCT trong hoạt động truyền thông nâng cao nhận thức về chính sách cho NCT. Với vai trò này đòi hỏi nhân viên xã hội phải có những hiểu biết về kiến thức pháp luật, các văn bản pháp lý liên quan đến chính sách trợ giúp và những kỹ năng chuyên môn trong tư vấn pháp lý kết nối NCT tới các cơ quan giải quyết, thụ lý hồ sơ, nhất là những NCT có các khó khăn, hạn chế về đi lại, giao tiếp, học vấn (không biết chữ) thì nhân viên xã hội cần có những cách thức trợ giúp hiệu quả.

Bên cạnh đó, có $48,5 \%$ số NCT cho biết trong hoạt động truyền thông nâng cao nhận thức về chính sách, nhân viên xã hội còn có vai trò "Kết nối NCT tiếp cận chính sách trợ giúp" trong vai trò này nhân viên xã hội đóng vai trò trung gian kết nối NCT với các thông tin về chính sách, các quyền lợi về chính sách và với các cơ quan thực thi chính sách địa phương và các cấp, tiếp nhận hồ sơ của NCT để giải quyết. Để thực hiện vai trò này, nhân viên xã hội là người nắm rất rõ quy trình, thủ tục chính sách và có quan hệ mật thiết với các cơ quan đơn vị thực thi chính sách trợ giúp xã hội.

Số NCT còn lại với 17,0\% số NCT tham gia trả lời, cho biết trong hoạt động truyền thông nâng cao nhận thức cho NCT về chính sách, nhân viên xã hội có vai trò "Biện hộ cho NCT gặp khó khăn về chính sách”, đây là vai trò mang tính chất chuyên môn đòi hỏi để thực hiện vai trò này nhân viên xã hội phải là người có tâm, nhiệt huyết, trách nhiệm và hiểu biểt về chính sách, hiểu biết về chính NCT mà họ đứng ra biện hộ giúp, cũng như thấu hiểu về những khó khăn mà NCT gặp phải khi tiếp cận chính sách. Đây chính là hoạt động cần được tăng cường và thực hiện thường xuyên, để hồ trợ tốt cho những NCT gặp khó khăn, nhất là những đối tượng NCT có những khó khăn và hạn chế trong đi lại, giao tiếp, sức khỏe yếu...

Như vậy, vai trò của nhân viên xã hội trong hoạt động truyền thông nâng cao nhận thức bao hàm nhiều vai trò quan trọng, từ vai trò cung cấp thông tin về chính sách, kết nối NCT tiếp cận chính sách trợ giúp cho đến những vai trò như tư vấn hỗ trợ giải quyết khó khăn, vướng mắc khi tiếp cận chính sách, biện hộ cho NCT gặp khó khăn về tiếp cận chính sách, giám sát việc thực hiện chính sách cho $\mathrm{NCT}$ và những hỗ trợ mang tính toàn diện, tổng hợp như hỗ trợ pháp lý về mọi mặt. Vì vậy, trong hoạt động này nhân viên xã hội là tác nhân đóng vai trò trung gian giúp cho NCT tiếp cận và tham gia chính sách trợ giúp xã hội một cách bền vững nhất. 


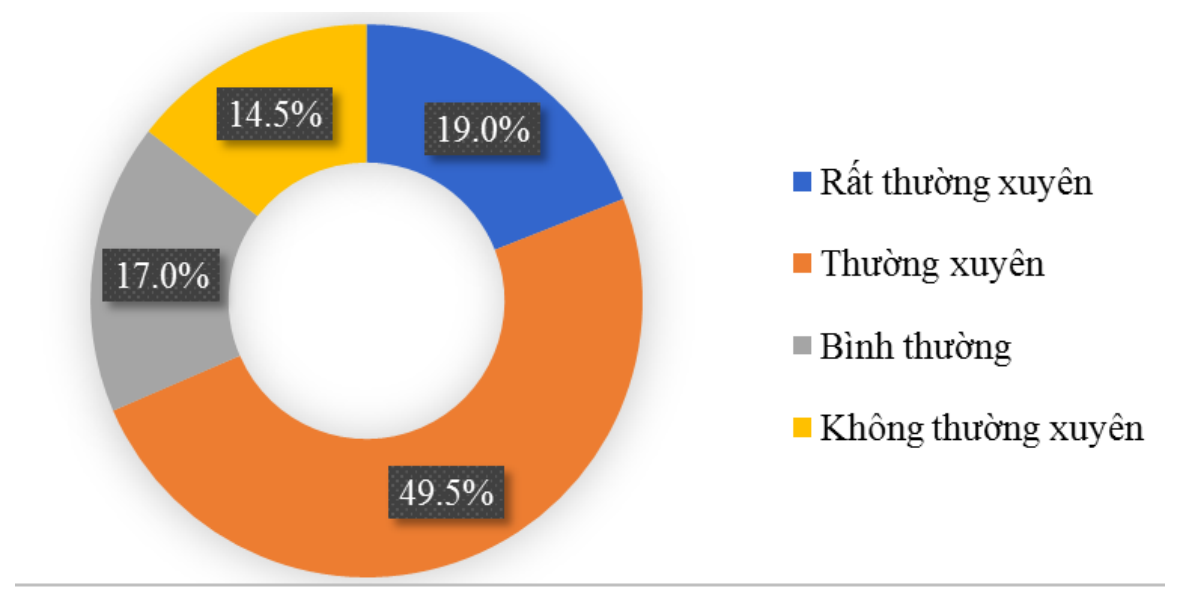

Biểu 2.6. Đánh giá của NCT về vai trò của nhân viên xã hội trong mô hình liên kết thế hệ tự giúp nhau.

Đơn vị: \%, N=200

(Nguồn: Kết quả khảo sát tại địa bàn nghiên cứu)

2.1.5. Đánh giá của NCT về vai trò của nhân viên xã họi trong mô hình liên thế hệ tự giúp nhau

Trong tổng số 200 NCT tham gia khảo sát thuộc địa bàn 2 xã Hoằng Lưu và xã Hoằng Trạch, số NCT đánh giá vai trò của nhân viên xã hội trong các hoạt động của mô hình liên thế hệ tự giúp nhau ở mức "Thường xuyên" chiếm tỷ lệ cao nhất với 49,5\% NCT tham gia trả lời, tập trung ở nhóm NCT thường xuyên nhận được các trợ giúp của nhân viên xã hội trong các hoạt động mà họ tham gia như: Hoạt động CSSK, hoạt động hỗ trợ sinh kế tạo việc làm, hoạt động giải trí - TDTT và hoạt động truyền thông nâng cao nhận thức về chính sách. Số NCT có đánh giá về vai trò của nhân viên xã hội ở mức "Rất thường xuyên" chiếm tỷ lệ cao thứ hai với 19,0\% số NCT tham gia trả lời, chủ yếu tập trung ở nhóm NCT có những khó khăn, hạn chế nhất định như: Sức khỏe yếu, bị hạn chế một số chức năng, có hoàn cảnh khó khăn... Vì vậy, những NCT này thường xuyên được sự quan tâm đặc biệt hơn của nhân viên xã hội. Chỉ tính riêng số NCT có đánh giá ở mức "Thường xuyên" và "Rất thường xuyên" đã chiếm tới gần $70,0 \%$ số NCT tham gia trả lời, điều này cho thấy những trợ giúp của nhân viên xã hội rất hiệu quả, luôn luôn có vai trò và dấu ấn của họ trong mỗi hoạt động của NCT trong mô hình.

Bên cạnh đó, có $17,0 \%$ số NCT có đánh giá về vai trò của nhân viên xã hội ở mức "Bình thường" và $14,5 \%$ số $\mathrm{NCT}$ có đánh giá về vai trò của nhân viên xã hội ở mức "Không thường xuyên", tập trung ở những nhóm NCT không tham gia thường xuyên vào các hoạt động trợ giúp trong mô hình liên thế hệ tự giúp nhau, việc không tham gia thường xuyên của họ vào mô hình do một số nguyên nhân khách quan và chủ quan như: suy nghĩ và nhận thức của họ về lợi ích của việc tham gia mô hình chưa đúng đắn, khoảng cách đi lại xa, hoặc những rào cản khác... chính điều này, đã khiến cho họ bị hạn chế nhận được những trợ giúp từ phía mô hình. Theo chia sẻ từ cán bộ quản lý và nhân viên xã hội đang hoạt động trong mô hình đó là, trong giai đoạn sắp tới sẽ làm tốt hơn nữa công tác vận động trợ giúp cho NCT có những có khó khăn riêng của bản thân bị hạn chế việc tham gia, để họ có cơ hội tham gia thường xuyên như những NCT khác.

Như vậy, nhận thức của NCT về vai trò của nhân viên xã hội được thể hiện thông qua chính hoạt động đánh giá về vai trò này, những đánh giá này hoàn toàn mang tính khách quan từ kết quả mà NCT nhận được trợ giúp ở mức độ như 
thế nào, kết quả này phản ánh vai trò của người nhân viên xã hội trong đó.

2.2. Đề xuất vai trò chuyên nghiệp của nhân viên CTXH trong mô hình liên thế hệ tụ giúp nhau

Từ việc phân tích vai trò bán chuyên nghiệp của nhân viên xã hội trong mô hình, trong nghiên cứu này tác giả đề xuất hoạt động CTXH chuyên nghiệp với vai trò của nhân viên CTXH trong mô hình liên thế hệ tự giúp nhau, bao gồm 6 vai trò chính: Vai trò vận động nguồn lực trợ giúp NCT; vai trò kết nối các hoạt động trợ giúp NCT; vai trò biện hộ, vận động chính sách trợ giúp NCT; vai trò truyền thông, giáo dục cho NCT; vai trò tham vấn, tư vấn cho NCT; vai trò chăm sóc, trợ giúp NCT. Những vai trò chuyên nghiệp này của nhân viên công tác xã hội sẽ giúp cho mọi hoạt động của mô hình trở nên hiệu quả và thuận lợi hơn, mô hình vận hành có dấu ấn của hoạt động công tác xã hội chuyên nghiệp, giúp cho mô hình khắc phục được những vấn đề tồn tại, để hướng tới xây dựng một mô hình chăm sóc - trợ giúp NCT dựa vào cộng đồng mang tính bền vững, đáp ứng được mong muốn, nguyện vọng của đông đảo NCT tại địa phương.

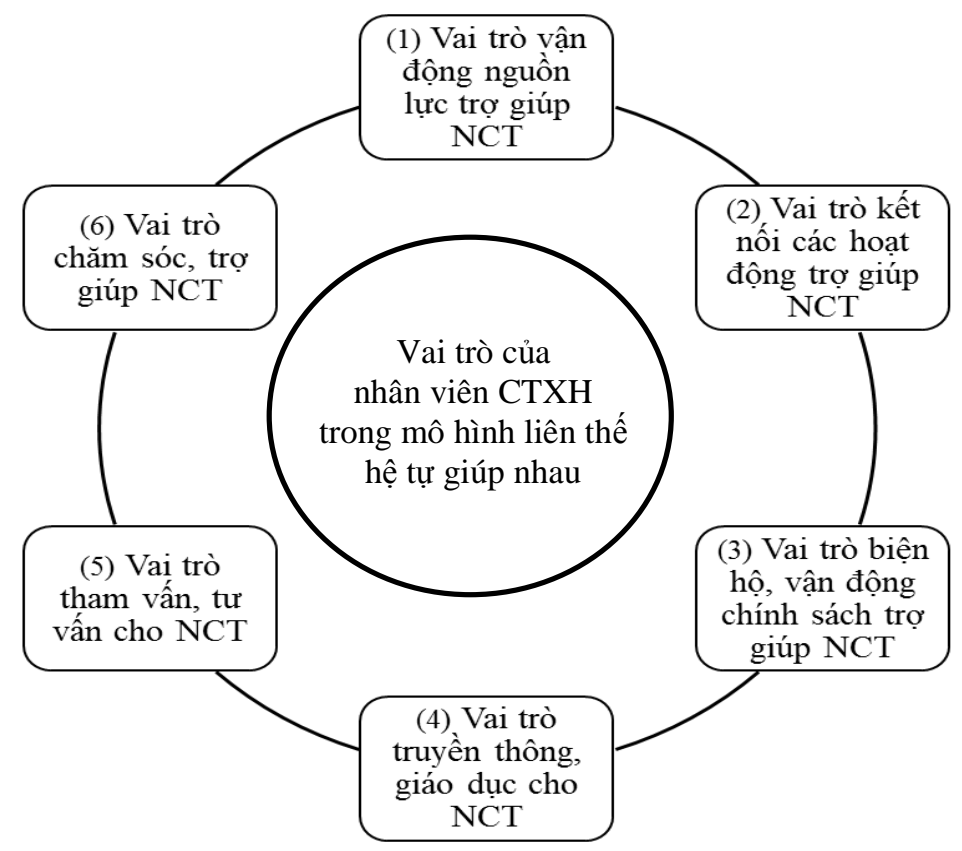

2.2.1. Vai trò vận động nguồn lục trợ giúp người cao tuổi

Chí̛c năng: Tìm kiếm những nguồn lực bên ngoài cộng đồng và chỉ ra những nguồn lực bên trong mô hình, nguồn lực từ chính NCT và gia đình NCT, để trợ giúp NCT trong mô hình, giúp họ cải thiện các vấn đề của bản thân một cách hiệu quả nhất.

Nhiệm vụ: Nhân viên CTXH đảm nhiệm vai trò trung gian tìm kiếm nguồn lực bên ngoài cộng đồng, từ phía các cơ quan, đơn vị, tổ chức, đoàn thể... Phát hiện các nguồn lực bên trong từ chính NCT, gia đình NCT và trong mô hình liên thế hệ tự giúp nhau, huy động tổng hợp các nguồn lực này để trợ giúp NCT.

\subsubsection{Vai trò kết nối các hoạt động trợ giúp} người cao tuổi

Chức năng: Kết nối và khai thác, giới thiệu cho NCT đang sinh hoạt trong mô hình liên thế hệ tự giúp nhau những dịch vụ trợ giúp, những 
chính sách trợ giúp và những tài nguyên sẵn có trong mô hình và trong cộng đồng, kết nối để trợ giúp cho NCT.

Nhiệm vu: Nhân viên $\mathrm{CTXH}$ làm cầu nối trung gian để kết nối các nguồn lực, các nguồn tài nguyên, các dịch vụ trợ giúp và các chính sách trợ giúp xã hội; kết nối NCT với các trợ giúp từ bên ngoài cộng đồng và từ phía các cơ quan, đơn vị, tổ chức, đoàn thể để NCT có thể tiếp cận được một cách hiệu quả.

\subsubsection{Vai trò biện hộ, vận động chính sách} trọ̣ giúp người cao tuổi

Chức năng: Giúp bảo vệ quyền lợi cho NCT để NCT được hưởng những dịch vụ, chính sách trợ giúp mà Nhà nước đã quy định, đặc biệt là những NCT bị hạn chế các chức năng xã hội; có những khó khăn, hạn chế về hiểu biết, về điều kiện sức khỏe (sức khỏe yếu, bị khuyết tật...), kể cả trong trường hợp NCT bị từ chối những dịch vụ, chính sách trợ giúp mà họ nằm trong đối tượng được hưởng, thì nhân viên CTXH đều là người đại diện cho $\mathrm{NCT}$ để biện hộ.

Nhiệm vu: Nhân viên CTXH đại diện cho quyền và lợi ích của $\mathrm{NCT}$, bảo vệ những quyền lợi mà $\mathrm{NCT}$ nằm trong diện được hưởng. Những NCT gặp khó khăn và bị hạn chế về các chức năng xã hội được nhân viên $\mathrm{CTXH}$ đại diện để làm việc với các cơ quan, đơn vị, tổ chức, đoàn thể mà NCT thuộc đối tượng được hưởng chính sách ở đấy.

\subsubsection{Vai trò truyền thông, giáo dục cho} người cao tuổi

Chức năng: Cung cấp, trang bị kiến thức kỹ năng nhằm thay đổi nhận thức, nâng cao năng lực cho NCT, giúp tăng cường hiểu biết, khả năng tự tin ra quyết định và có năng lực để giải quyết những khó khăn của bản thân, để tham gia các hoạt động của mô hình liên thế hệ tự giúp nhau một cách hiệu quả và thuận lợi nhất.

Nhiệm vu: Nhân viên CTXH tổ chức hoạt động truyền thông, tập huấn, giáo dục nhằm trang bị cho NCT những kiến thức - kỹ năng về CSSK, những hiểu biết về chính sách trợ giúp xã hội, những kỹ thuật về sản xuất (trồng trọt, chăn nuôi trong mô hình), cách xây dựng đời sống văn hóa - tinh thần phong phú... Từ đó, NCT có thể mang những kiến thức, kỹ năng, kỹ thuật được trang bị, để vận dụng hiệu quả vào quá trình tham gia các hoạt động của mô hình.

\subsubsection{Vai trò tham vấn, tư vấn cho ngườ cao tuổi}

Chức năng: Tham vấn, tư vấn cho những NCT có khó khăn về tâm lý xã hội (ví dụ như những NCT sống cô đơn, những NCT bị trầm cảm...), giúp NCT ứng phó hiệu quả và vượt qua được những căng thẳng, khủng hoảng và rào cản tâm lý, để có được những suy nghĩ, nhận thức và hành vi tích cực, giúp NCT giảm bớt thiệt thòi và hòa nhập với cuộc sống tốt hơn.

Nhiệm vu: Nhân viên CTXH là người trực tiếp thực hiện các hoạt động tham vấn, tư vấn cho NCT, thông qua những hoạt động giao tiếp, thăm hỏi, động viên... nhằm chia sẻ, đồng cảm với những khó khăn của $\mathrm{NCT}$, cùng với $\mathrm{NCT}$ đề ra những biện pháp trợ giúp tích cực giúp NCT hòa nhập cộng đồng tốt hơn, tăng cường sự tham gia của những NCT thuộc nhóm này vào các hoạt động cộng đồng trong mô hình liên thế hệ tự giúp nhau.

\subsubsection{Vai trò chăm sóc, trọ giúp cho người cao tuổi \\ Chức năng: Chăm sóc, trợ giúp những NCT} có khó khăn, hạn chế do sức khỏe yếu, bệnh tật nhiều, có những tổn thương tâm lý, bị khuyết tật... Cung cấp dịch vụ chăm sóc, trợ giúp và kết nối những dịch vụ chăm sóc, trợ giúp mà NCT có thể tiếp cận được.

Nhiệm vu: Nhân viên CTXH phối với với gia đình NCT thực hiện các hoạt động chăm sóc, trợ giúp NCT tại nhà, những NCT sống cô đơn, hoàn cảnh khó khăn thì cung cấp và kết nối cho họ những dịch vụ chăm sóc, trợ giúp thường xuyên hơn. Từ đó, giúp NCT giảm bớt những thiệt thòi, khó khăn, hòa nhập với cộng đồng; những trường hợp NCT có các khó khăn và hạn chế về sức khỏe, nhân viên CTXH phối hợp với NCT trong mô hình liên thế hệ tự giúp 
nhau tổ chức các hoạt động thăm hỏi, động viên, quan tâm lẫn nhau, giúp NCT sống hòa nhập và thoải mái hơn.

Như vậy, vai trò chuyên nghiệp của nhân viên CTXH trong mô hình liên thế hệ tự giúp nhau bao hàm tổng hợp rất nhiều vai trò như: Vai trò vận động nguồn lực trợ giúp NCT; vai trò kết nối các hoạt động trợ giúp NCT; vai trò biện hộ, vận động chính sách trợ giúp NCT; vai trò truyền thông, giáo dục cho $\mathrm{NCT}$; vai trò tham vấn, tư vấn cho $\mathrm{NCT}$; vai trò chăm sóc, trợ giúp NCT. Việc thực hiện thường xuyên các vai trò này giúp cho hoạt động can thiệp - trợ giúp NCT đạt được hiệu quả cao hơn. Trong định hướng phát triển của mô hình cần có những hoạt động đào tạo, tập huấn nghiệp vụ CTXH thường xuyên cho đội ngũ cán bộ, nhân viên, tình nguyện viên - gọi chung là nhân viên xã hội, để nâng cao kiến thức - kỹ năng chuyên môn nghiệp vụ và năng lực làm việc của đội ngũ này, từ đó giúp nâng cao hiệu quả can thiệp - trợ giúp cho NCT. Đồng thời, thu hút đội ngũ nhân viên $\mathrm{CTXH}$ được đào tạo bài bản về chuyên ngành CTXH ở các cơ sở đào tạo, về làm việc trong mô hình liên thế hệ tự giúp nhau để đảm nhận những vai trò, vị trí trong mô hình, giúp mô hình vận hành hiệu quả và chuyên nghiệp hơn.

\section{Một số kiến nghị thực tiễn}

3.1. Đối với ban quản lý mô hình liên thế hệ tụ giúp nhau tại 2 xã Hoằng Luu và Hoằng Trach

Tăng cường các hoạt động phối hợp giữa cán bộ đang làm việc trong mô hình với cán bộ chính quyền địa phương, để hoạt động can thiệp - trợ giúp NCT đạt hiệu quả cao hơn, bền vững hơn.

Thường xuyên tổ chức các buổi tập huấn nâng cao năng lực về nghiệp vụ chuyên môn về quản lý mô hình, can thiệp - trợ giúp NCT cho đội ngũ cán bộ, nhân viên đang làm việc mô hình liên thế hệ tự giúp nhau.
Đẩy mạnh phát triển các hoạt động của mô hình liên thế hệ tự giúp nhau theo chiều sâu, trong đó phối hợp vai trò cộng tác từ nhiều phía như: gia đình, chính quyền địa phương, các tổ chức, ban ngành, đoàn thể, cộng tác viên, tình nguyện viên trong và ngoài mô hình. Trong đó chú trọng vai trò của gia đình và lấy vai trò của gia đình làm trung tâm, bởi việc chăm sóc người cao tuổi là trách nhiệm đặc biệt của gia đình, nhằm tạo nền tảng vững chắc cho hoạt động chăm sóc, hỗ trợ lâu dài.

Đa dạng hóa hình thức và hoạt động can thiệp - trợ giúp cho NCT thuộc các nhóm tuổi khác nhau; cần có những chính sách trợ giúp phù hợp đối với từng nhóm NCT, cụ thể: nhóm tuổi từ 60-69 cần chú trọng việc "phát huy là chính"; người cao tuổi thuộc nhóm tuổi từ 7079 cần tập trung "vừa chăm sóc vừa phát huy"; người cao tuổi thuộc nhóm tuổi từ 80 trở lên lấy việc "chăm sóc là chính". Nhằm có những hình thức can thiệp - trợ giúp đa dạng, hiệu quả, phù hợp với đặc thù riêngcủa từng nhóm $\mathrm{NCT}$.

\section{2. Đối với nhân viên xã hội trong mô hình liên thế hệ tư giúp nhau}

Thường xuyên tham gia các hoạt động đào tạo, tập huấn nâng cao năng lực, kỹ năng, chuyên môn nghiệp vụ trong can thiệp - trợ giúp NCT. Đặc biệt là, trong lĩnh vực công tác xã hội.

Tăng cường các hoạt động giám sát, các hoạt động thực địa dưới địa bàn để hỗ trợ NCT tốt hơn trong hoạt động sinh kế tạo việc làm, giảm thiểu rủi ro trong hoạt động sản xuất cho NCT.

Cập nhật và ứng dụng các thông tin, kiến thức, kỹ năng, kỹ thuật mới để tập huấn, chia sẻ, can thiệp - trợ giúp cho NCT tốt hơn.

\section{3. Đối với gia đình người cao tuổi}

Gia đình NCT cần tạo điều kiện thuận lợi và giúp đỡ $\mathrm{NCT}$ trong gia đình tiếp cận các chương trình, hoạt động chăm sóc - trợ giúp của mô hình một cách tốt nhất. Phối hợp với cán bộ, nhân viên mô hình vận động NCT tham gia tích 
cực vào các hoạt động của mô hình liên thế hệ tự giúp nhau.

\section{4. Đối với người cao tuổi}

Người cao tuổi cần chủ động tham gia hoạt động do mô hình liên thế hệ tự giúp nhau tổ chức. Trang bị, cập nhật các kiến thức, kỹ năng, kỹ thuật mà cán bộ, nhân viên trong mô hình tuyên truyền, chia sẻ, tập huấn... Nhằm tạo nền tảng, điều kiện tốt cho hoạt động can thiệp - trợ giúp của mô hình diễn ra hiệu quả.

\section{Tài liệu tham khảo}

[1] Tổ chức Hỗ trợ Người cao tuổi Quốc tế (2013), Dự án chăm sóc người cao tuổi dựa vào cộng đồng, Dự án điều tra cơ bản, Thanh Hóa.

[2] Nguyễn Văn Đồng, Câu lạc bộ liên thế hệ tự giúp nhau - Mô hình chăm sóc, phát huy vai trò người cao tuổi, Tạp chí Mặt trận Tổ quốc Việt Nam, số 132 (2014) 69.

[3] Nguyễn Văn Đồng, Nghề công tác xã hội với người cao tuổi, triển vọng và thách thức, Tạp chí Mặt trận Tổ quốc Việt Nam, số 139 (2015) 8.

\title{
Managing the Elderly Inter-generational Self-help Model and the Role of Social Work
}

\author{
Nguyen Van Dong \\ Vietcess International Skill Training Centre, \\ Building Licogi 13, 164 Khuat Duy Tien, Thanh Xuan, Hanoi, Vietnam
}

\begin{abstract}
Thanh Hoa province is a pioneer in inter-generational self-help, a model of communitybased care and support for older people; it mobilizes commuinty's care, support for the elderly and promotes their role. Hoang Hoa is the first district of Thanh Hoa province with this type of model. Under this model, the elderly are helped through four main activities: health care, livelihood employment creation support, entertainment - sports, and the elderly policy awareness enhancement. The study was carried out in Hoang Luu and Hoang Trach communes in Hoang Hoa district with interrelated models of self-help. The sample was 200 elderly people aged 60-80, living in an intergenerational model of self-help in the surveyed area.
\end{abstract}

Keywords: Inter-generational, self-help, elderly, social work. 